\title{
Reducing intraoperative lower segment blood loss in placenta previa with Ashok Anand stitch
}

\author{
Ashok R. Anand, Deepti Gupta*, Anju Prasad
}

Department of Obstetrics \& Gynecology, Grant Medical College and Sir JJ Group of Hospital, Mumbai-400008, India

Received: 1 February 2013

Revised: 9 March 2013

Accepted: 22 March 2013

\author{
*Correspondence: \\ Dr. Deepti Gupta, \\ E-mail: drdeepti_02@yahoo.com
}

() 2013 Anand AR et al. This is an open-access article distributed under the terms of the Creative Commons Attribution License, which permits unrestricted use, distribution, and reproduction in any medium, provided the original work is properly cited.

\begin{abstract}
Background: To avoid the need for blood transfusions and reducing complications in cases of placenta previa during cesarean section delivery by a new simple innovative technique developed by Dr ASHOK ANAND known as Ashok Anand's stitch.

Methods: This stitch is based on the reasoning that taking the stitch bilaterally occludes the collaterals supplying the lower segment. As these are end arteries, their occlusion causes hemostasis in the lower segment. Sample size: 20 cases in each study group. Blood loss was estimated by standardized visual method (fixed container and mop).

Results: By applying this technique in 20 cases, there was significant reduction in the blood loss compared to the control group, thereby reducing the need for blood transfusion $(p$ value $<0.05)$.

Conclusions: Ashok Anand's stitch is a simple and effective technique in controlling lower segment bleeding in cases of placenta previa during cesarean section thus avoiding the need for blood transfusions for operative blood loss and obstetric hysterectomy. The technique is easy to apply, less invasive and does not require any special instruments. It can be life-saving.
\end{abstract}

Keywords: Postpartum hemorrhage, Placenta previa, Lower segment bleeding

\section{INTRODUCTION}

Obstetrical hemorrhage still remains a leading cause of direct maternal morbidity and mortality. In countries with fewer resources the contribution of hemorrhage to maternal mortality rates is even more striking (Jegasothy, 2002; Rehman and co-workers, 2002). ${ }^{1}$ Obstetrical hemorrhage accounts for almost half of all postpartum deaths in developing countries (Lalonde, 2006; McCormick and associates, 2002). ${ }^{2}$ As far as placenta previa is concerned, according to the birth certificate data in United States in 2003, placenta previa complicated almost 1 in 300 deliveries (Martin and coworkers, 2005) ${ }^{3}$ and similar incidence was reported in other studies.
Bleeding from the placental bed in cases of placenta previa is a commonly faced, less discussed issue till date. The highly vascular and friable lower segment which forms the placental bed is slow to retract and the greater the time it takes, more severe is the blood loss. To add to it, taking hemostatic sutures in the placental bed is difficult and the chances of placental bed tissue cut through by sutures are high, leading to further blood loss. Devascularization of lower segment by bilateral uterine artery ligation is helpful, but only to some extent. In developed countries and at wellequipped centers where facilities of blood and blood products, intensive care and skilled surgeons are available, such complications can be managed with help of uterine artery catheterization, ballooning and embolization. This also requires specialized, expensive equipments and technical expertise. In underdeveloped and developing countries with scant resources and sometimes even in 
developed countries with resources, it can become a nightmare for everyone.

Ashok Anand's stitch is a simple, less invasive, cost effective, time saving and rapidly effective method to control lower uterine segment blood loss in such cases. It was discovered on the operating table on 19 Nov, 2007 by Dr. Ashok Anand, Professor in Obstetrics and Gynaecology, Grant Medical College and Sir JJ Group of Hospitals, Mumbai, in an attempt to control postpartum hemorrhage in a case of previous cesarean delivery with central morbidly adherent placenta previa. This technique has been successfully applied to several cases of placenta previa operated in the last 3 years at JJ Hospital with no apparent complications till date, no requirement of blood transfusion for operative blood loss and no obstetric hysterectomies. The woman, on whom this technique was performed for the first time, recently delivered her third child successfully by cesarean.

\section{METHODS}

Study design: Three year hospital based controlled clinical study.

Place of study: Sir JJ group of Hospital Mumbai.

Sample size: 20 cases were taken in which Ashok Anand's stitch was applied and these were compared with 20 other randomly selected cases of major placenta previa delivered during period of three years at JJ hospital. The two groups were compared on the basis of blood loss, need for blood transfusion and obstetric hysterectomy. Estimation of blood loss was done by standardized visual method.

\section{Technique}

The technique can be described as follows:

1. The patient is kept in a supine position under spinal/general anesthesia.

2. After delivery of the baby by lower segment cesarean section, umbilical cord is clamped and cut and uterus is exteriorized with placenta in situ.

3. Both uterine angles are secured with braided coated Polyglactin 910 number 1 on round body needle ( $40 \mathrm{~mm}^{1 / 2}$ circle).

4. Bilateral uterine arteries (descending cervical branch) are ligated with the same suture. Bladder is pushed down further.

5. The assistant holds the uterus in central upright position. A spade or any other retractor can be used to retract the intestines behind the uterus to avoid injury.

6. Polyglactin 910 number 1 is mounted on a straight needle (18 no triangular straight) or surgeons preference and inserted into the cervix, from anterior to posterior, $1 \mathrm{~cm}$ above the level of lateral fornix and $0.5 \mathrm{~cm}$ medially from lateral cervical musculature.
7. The same needle and suture is reinserted from posterior to anterior $0.5 \mathrm{~cm}$ below the lower edge of the uterine incision on the same side.

8. The knot is then tied and secured midway between the two points.

9. Similar steps are repeated on the other side.

10. As soon as the sutures are taken, the lower segment is devascularized and then the placenta can be easily removed even if it is morbidly adherent.

11. The placental bed is found to be dry with no active bleeding.

12. The uterine incision is then closed.

The accompanying figures illustrate this technique (Figure 1-5).

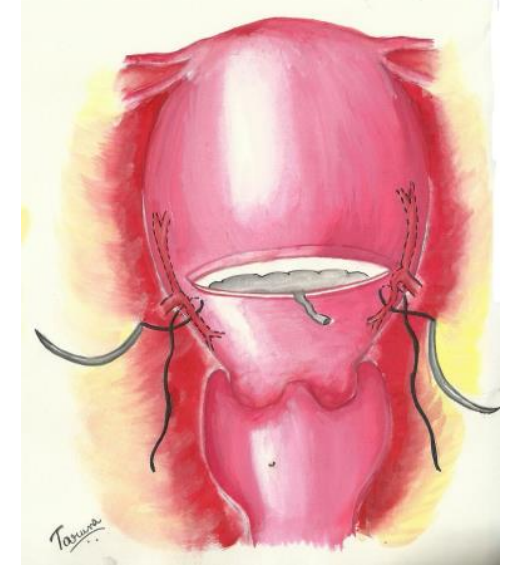

Figure 1: Uterine artery ligation; Bilateral uterine arteries (descending cervical branch) are ligated with braided coated Polyglactin 910 on number 1 round body needle $(40 \mathrm{~mm}, 1 / 2$ circle).

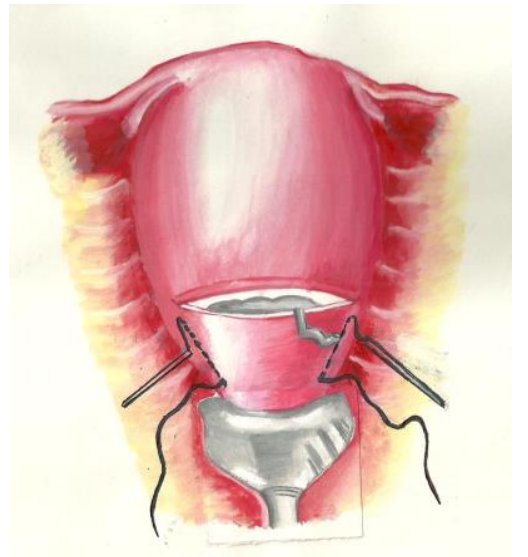

Figure 2: Ashok Anand's stitch- Anterior view; Polyglactin 910 number 1 is mounted on a straight needle (18 no triangular straight). Needle is inserted into the cervix, from anterior to posterior, $1 \mathrm{~cm}$ above

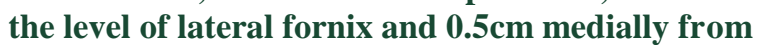
lateral cervical musculature. The same needle and suture is reinserted from posterior to anterior $0.5 \mathrm{~cm}$ below the lower edge of the uterine incision on the same side. 


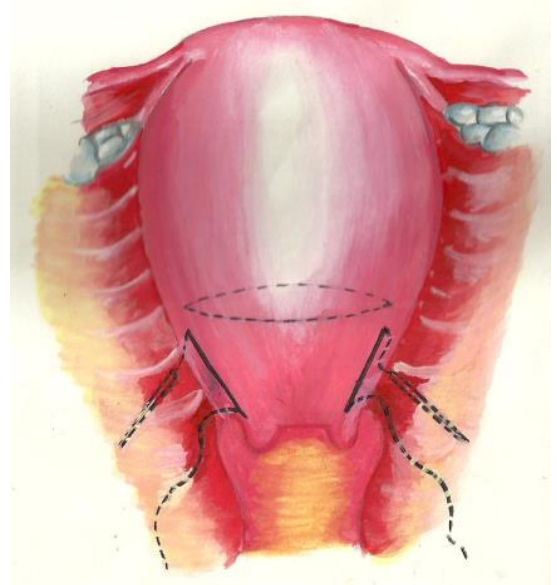

Figure 3: Ashok Anand's Stitch- Posterior View; Posterior view of uterus showing the stitch. The needle exits posteriorly, $1 \mathrm{~cm}$ above the level of lateral fornix on the same side and reenters the uterus from posterior to anterior $0.5 \mathrm{~cm}$ below the level of lower edge of uterine incision.

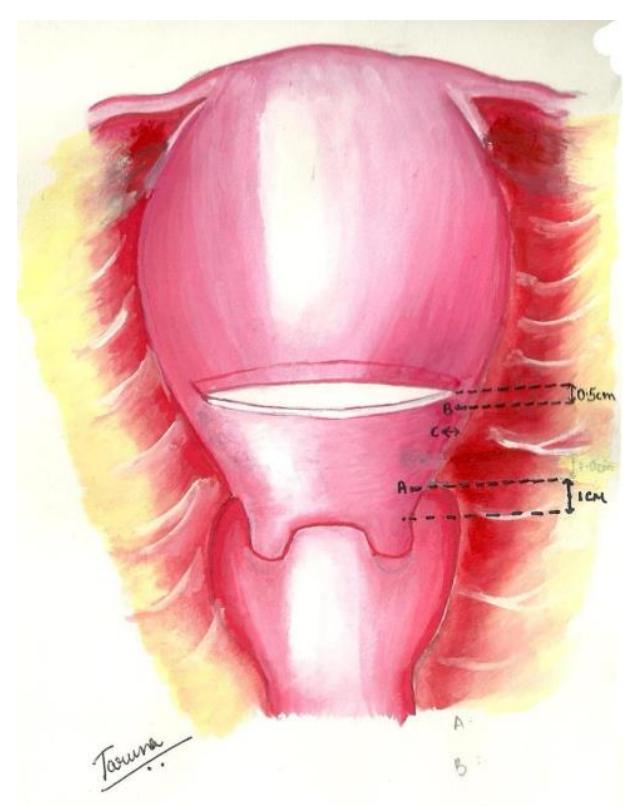

Figure 5: Schematic diagram showing the entry and exit points in Ashok Anand's stitch; A- Point of insertion of needle from anterior to posterior $(1 \mathrm{~cm}$ above the level of lateral fornix, $0.5 \mathrm{~cm}$ medially to lateral border of cervix), B-Point of reinsertion of needle from posterior to anterior $(0.5 \mathrm{~cm}$ below the lower margin of uterine incision, $2 \mathrm{~cm}$ medial to the lateral uterine margin), C-Point midway between $\mathrm{A}$ and $B$ anteriorly where the knot is tied.

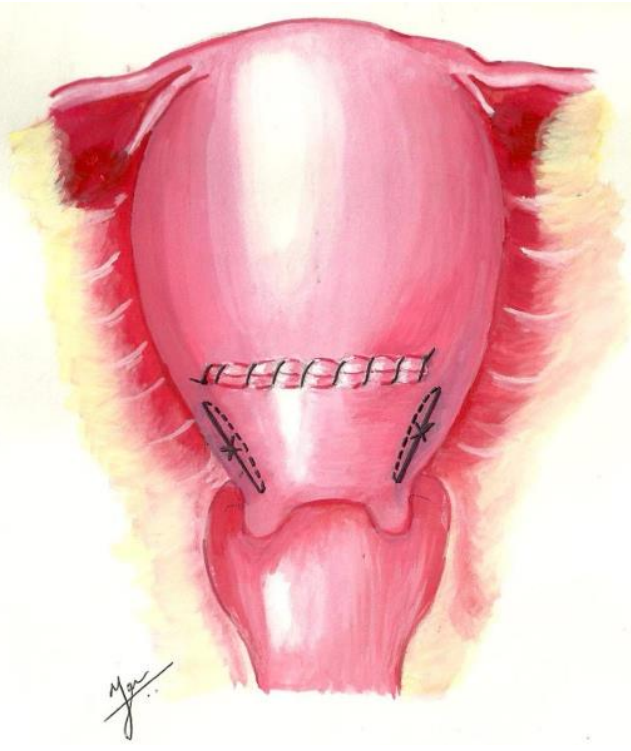

Figure 4: Ashok Anand's stitch- final view; Anterior view of the uterus showing the suture tied midway between the entry and exit points.

\section{RESULTS}

20 cases in which Ashok Anand stitch was taken were compared with 20 randomly selected placenta previa cases in which stitch was not taken. In all the cases placenta previa was of Grade 3 or Grade 4. Comparison was done on the basis of blood loss, need for blood transfusion and any other maternal morbidity.

(1) Analysis of data of blood loss in with stitch and without stitch cases

One way ANOVA

\begin{tabular}{|llll|}
\hline & Df & F & $p$ value \\
\hline Between Groups & 12 & 3.352 & 0.05 \\
\hline Within Groups & 7 & & \\
\hline Total & 19 & & \\
\hline
\end{tabular}

Without stitch blood loss

\begin{tabular}{|l|lllll|}
\hline & N & Minimum & Maximum & Mean & Std. Deviation \\
\hline Without stitch & 20 & 900.00 & 2800.00 & 1257.5000 & 436.8774 \\
\hline Valid N (list wise) & 20 & & & & \\
\hline
\end{tabular}


With stitch Blood loss.

\begin{tabular}{|l|lllll|}
\hline & N & Minimum & Maximum & Mean & Std. Deviation \\
\hline With stitch & 20 & 200.00 & 4200.00 & 687.5000 & 909.9617 \\
\hline Valid N (list wise) & 20 & & & & \\
\hline
\end{tabular}

By using one way ANOVA method, it is found that blood loss in cases without stitch is more than blood loss in cases with Ashok Anand stitch. The data is found to be significant with $\mathrm{f}=3.352(\mathrm{p}=0.05)$.

\section{(2) Analysis of amount of blood loss in two groups}

\begin{tabular}{|lll|}
\hline Blood loss & $\begin{array}{l}\text { Blood loss } \\
<\mathbf{1 0 0 0}\end{array}$ & $\begin{array}{l}\text { Blood loss } \\
>\mathbf{1 0 0 0}\end{array}$ \\
\hline Without Stitch & 3 & 17 \\
\hline With Stitch & 16 & 4 \\
\hline
\end{tabular}

In a group in which Ashok Anand stitch was taken, by using standardized visual estimation of blood loss using fixed mop and container, it was found that in 16 cases blood loss was less than $1000 \mathrm{ml}$ and in 4 cases it was more than $1000 \mathrm{ml}$. While using the same method in the control group in which stitch was not taken, it was found that in only 3 cases blood loss was less than $1000 \mathrm{ml}$ and in rest 17 cases blood loss was more than $1000 \mathrm{ml}$.

\section{(3) Blood transfusion}

\begin{tabular}{|lll|}
\hline $\begin{array}{l}\text { Blood } \\
\text { transfusion }\end{array}$ & $\begin{array}{l}\text { Required } \\
\text { Blood }\end{array}$ & $\begin{array}{l}\text { Not Required } \\
\text { Blood }\end{array}$ \\
\hline Without Stitch & 20 & 0 \\
\hline With Stitch & 9 & 11 \\
\hline
\end{tabular}

\begin{tabular}{|ll|}
\hline Chi-Square & 5.95 \\
\hline df & 2 \\
\hline$p$ value & 0.05 \\
\hline
\end{tabular}

In 20 cases in which Ashok Anand stitch was taken, the need for blood transfusion was required in 9 cases, while in the control group, blood transfusion was required in all the 20 cases. By using chi square test it was found that the need for blood transfusion was higher in the group without stitch and significant with chi square= 5.95 and 2 degrees of freedom ( $p$ value: 0.05 ).

In all the cases of placenta previa in which Ashok Anand stitch was taken and blood transfusion was required, it is mainly because of either anemia in women or due to departmental protocol of arranging blood prophylactically.

\section{(4) Post stitch blood loss}

\begin{tabular}{|llllll|}
\hline & N & Minimum & Maximum & Mean & Std. Deviation \\
\hline Post stitch Blood loss & 20 & 10.00 & 200.00 & 68.0000 & 51.0521 \\
\hline Valid N (list wise) & 20 & & & & \\
\hline
\end{tabular}

In placenta previa, blood loss is mainly after the separation of the placenta and that too from the lower segment because lower segment is not able to contract. Surgeons try to control the blood loss by taking stitches in the placental bed or approximating the lower segment or inverting the cervix and suturing it on the lower segment to control the bleeding. Ashok Anand stitch is based on the reasoning that taking the stitch bilaterally occludes the collaterals supplying the lower segment. As these are end arteries, their occlusion causes hemostasis in the lower segment.
Blood loss was measured after taking the stitch. The maximum blood loss was $200 \mathrm{ml}$ and minimum was $10 \mathrm{ml}$, with mean of $68 \mathrm{ml}$. One case, in which stitch could not be taken, has been excluded from the study.

\section{(5) Maternal morbidity}

Here maternal morbidity was measured in terms of need for obstetric hysterectomies.

\begin{tabular}{|llll|l|}
\hline $\begin{array}{l}\text { Maternal } \\
\text { morbidity }\end{array}$ & $\begin{array}{l}\text { Obstetric hysterectomy } \\
\text { required }\end{array}$ & $\begin{array}{l}\text { Obstetric hysterectomy } \\
\text { not required }\end{array}$ & Total cases & Percentage \\
\hline Without Stitch & 3 & 17 & 20 & 15 percentages \\
\hline With Stitch & 0 & 20 & 20 & 0 percentage \\
\hline
\end{tabular}


Of the 20 cases in the control group, 3 required obstetric hysterectomy i.e. $15 \%$, while none of the cases in which the stitch was taken, required an obstetric hysterectomy.

As we have seen in the analysis above, blood loss in the control group was significantly high as compared to the case group. All the 20 cases in the control group required blood transfusion, while only 9 cases required blood transfusion in the study group. Moreover 3 obstetric hysterectomies were done in the control group as compared to zero in the study group.

Hence, the results clearly suggest that the stitch can be very useful as well as helpful in achieving hemostasis in cases of placenta previa.

\section{DISCUSSION}

Every minute a woman dies as a result of pregnancy or childbirth. The loss per annum of 500,000 women is mind boggling. A maternal death is the outcome of a chain of events and disadvantages throughout a woman's life. Every time a woman in the third world becomes pregnant, her risk of death is 200 times higher than that of a woman in the developed world. The world has come a long way from the time when a woman surviving childbirth was considered to be blessed with a 'second life' to the present, where the WHO theme for the year 2005 stated, "every mother counts!" A majority of maternal deaths occurs in Asia $(253,000)$ and Africa $(251,000)$. Thirteen countries account for $67 \%$ of all maternal deaths. India has the dubious distinction of having the highest estimated number of maternal deaths in any country $(136,000)$. Developed countries in contrast have a maternal mortality ratio of around 20 per 100,000 live births. ${ }^{4}$

In India, hemorrhage (25.6 percent) ranks first as the cause of maternal death, followed by sepsis (13 percent), toxemia of pregnancy (11.9 percent), abortions (8 percent) and obstructed labor (6.2 percent) while other causes together total 35.3 percent.

Postpartum hemorrhage complicates approximately $4 \%$ of vaginal and $6 \%$ of cesarean deliveries. ${ }^{5}$ The WHO estimates that postpartum haemorrhage accounts for nearly $30 \%$ of maternal deaths worldwide with an estimated 20 million cases annually. ${ }^{6}$

In cases of placenta previa, as the lower uterine segment is less muscular, contraction and retraction, which result in the occlusion of the sinuses of the placental bed, are inadequate, and intra-operative hemorrhage is therefore not uncommon. ${ }^{7}$ Where haemostasis is difficult to achieve, bleeding sinuses can be over sewn with atraumatic sutures. ${ }^{8}$ If this is unsuccessful, packing the uterus is possible, but the major disadvantage is that, by leaving the pack in situ during closure of the uterus, the bleeding may continue but remain concealed for some time as the pack is soaking through. The use of balloons with a tamponading effect on the bleeding placental bed or intramyometrial injection of prostaglandin F2 $\alpha$ has been shown to be useful in such cases. ${ }^{9}$ More recently, where the facilities are available, uterine artery embolization has been used with excellent results. The difficulty with this is the lack of availability of the facilities and the interventional radiologist at the time of delivery. If the bleeding remains uncontrollable, ligation of the internal iliac artery or even hysterectomy may be necessary as the last resort.

Morbidly adherent placenta occurs in about 1 in 2500 deliveries. There has been a marked increase in the last 50 years, probably secondary to the increase in Cesarean section delivery rates. ${ }^{10}$

Risk factors include implantation in the lower uterine segment over a previous surgical scar or excessive uterine curettage resulting in Ashermann's syndrome. Placenta previa is identified in one-third of cases, and $25 \%$ of women have had a previous Cesarean delivery. Nearly one-quarter have previously undergone curettage and another quarter are grand multipara. ${ }^{11}$ Although uncommon, they are associated with a significantly high maternal morbidity and sometimes mortality primarily due to hemorrhage, uterine perforation, infection and the associated surgical complications. ${ }^{12}$

Ashok Anand's stitch is a simple and effective new technique to control lower uterine segment blood loss in placenta previa even if it is morbidly adherent. This stitch is based on the reasoning that taking the stitch bilaterally as mentioned above occludes the collaterals supplying the lower segment. As these are end arteries, their occlusion causes hemostasis in the lower segment.

\section{CONCLUSION}

Ashok Anand's stitch can thus be used in cases of placenta previa during cesarean delivery as a simple and effective method for controlling postpartum hemorrhage. The Ashok Anand stich is very effective as it devascularises lower segment even before the placental sinuses are open. It is easy to take $\&$ does not require special expertise; it is not time consuming, does not require any special material or instrument $\&$ does not affect the fertility. It can be of major help to the surgeons, mainly in developing countries and in the setting of limited resources for avoiding blood transfusions and complications like obstetric hysterectomy.

Funding: No funding sources

Competing interests: None declared

Ethical approval: The study was approved by the Institutional Ethics Committee, Grant Medical College and Sir J.J. Group of Hospital, Mumbai 


\section{REFERENCES}

1. Jegasothy R. Sudden maternal deaths in Malaysia: a case report. J Obstet Gynaecol Res 2002;28:186-93.

2. Lalonde A, Davis BA, Acosta A, et al. Postpartum hemorrhage today: ICM/FIGO initiative 2004-2006. Int J Obstet Gynaecol 2006;94:243-53.

3. McCormick ML, Sanghvi HC, Kinzie B, McIntosh N. Preventing postpartum hemorrhage in low resource settings. Int $\mathrm{J}$ Gynaecol Obstet 2002;77:267-75.

4. WHO, UNICEF, UNFPA. Maternal mortality in 2000: Estimates developed by WHO, UNICEF, UNFPA. Geneva: WHO, 2003.

5. Mousa HA, Alfirevic Z. Treatment for primary postpartum haemorrhage. Cochrane Database Syst Rev 2007;(1):CD003249.

6. WHO 1999. Causes of maternal deaths, latest year available. World Health Report 106 Geneva: WHO.
7. Williamson HC, Greeley AV. Management of placenta praevia: 12 year study. Am J Obstet Gynecol 1945;50:987-91.

8. Scott JS. Antepartum hemorrhage. In Whitefield CR, ed. Dewhurst's Textbook of Obstetrics and Gynaecology for Postgraduates, 4th edn. Oxford: Blackwell, 1986.

9. Myerscough PR. Munro Kerr's Operative Obstetrics, 10th edn. London: Bailliere Tindall, 1982.

10. Comstock CH. Antenatal diagnosis of placenta accreta: a review. Ultrasound Obstet Gynecol 2005;26:89-96.

11. Fox H. Placenta accreta, 1945-1969. Obstet Gynecol Surv 1972;27:475-90.

12. Zelop CM, Harlow BL, Frigoletto FD Jr, Safon LE, Saltzman DH. Emergency peripartum hysterectomy. Am J Obstet Gynecol 1993;168:1443-8.

DOI: $10.5455 / 2320-1770$. ijrcog20130605

Cite this article as: Anand AR, Gupta D, Prasad A. Reducing intraoperative lower segment blood loss in placenta previa with Ashok Anand stitch. Int J Reprod Contracept Obstet Gynecol 2013;2:13540. 